\title{
TINJAUAN KUAT TEKAN DAN MODULUS ELASTISITAS BETON PADA CAMPURAN DIATOMAE SEBAGAI ADITIF
}

\author{
Emi Maulani \\ Jurusan Teknik Sipil Universitas Malikussaleh \\ email:emi.maulani@gmail.com
}

\begin{abstract}
Abstrak
Tanah Diatomae dari Lampanah Kabupaten Aceh Besar Provinsi Aceh disusun dari diatomit dengan kandungan silika $\mathrm{SiO}_{2} 62.28 \%$, yang sesuai dengan European Standards (EN) 197-1 karena memiliki reactive silica (RS) diatas $25 \%, \mathrm{CaO} 8.28 \%, \mathrm{Fe}_{2} \mathrm{O}_{3} 1.79 \%$, dan $\mathrm{Al}_{2} \mathrm{O}_{3} 9.52 \%$. Berdasarkan Dinas Pertambangan dan Energi Provinsi Aceh tahun 2012, sebaran tanah diatomae di Kabupaten Aceh Besar sangat berlimpah dengan estimasi 40.353.700.00 ton, tanah diatomae memiliki sifat pozzolan yang mirip dengan bahan pozzolan lainnya seperti fly ash dan metakaolin dengan berat jenis yang ringan 1.5. Pada penelitian ini tanah diatomae adalah bahan utama yang digunakan sebagai Aditif atau bahan tambah pada pembuatan beton. Tujuan penelitian ini adalah untuk menguji tanah diatomae sebagai bahan tambahan alternatif yang dapat digunakan pada pembuatan beton mutu normal dan membandingkan dengan karakteristik beton yang sesuai standar mutu beton normal tanpa bahan tambahan tanah diatomae. Benda uji yang dibuat berupa silinder dengan ukuran diameter $100 \mathrm{~mm}$ dan tinggi $200 \mathrm{~mm}$ dengan faktor air semen FAS 0.30 dengan persentase kadar substitusi tanah diatomae 0\%, 5\%, $10 \%$, dan $15 \%$. Pengujian dilakukan pada umur 7 hari, 28 hari dan 56 hari.

Nilai kuat tekan beton mengalami penurunan sebanding dengan penambahan kadar tanah diatomae terhadap semen. Namun persentase diatomae sampai $15 \%$ nilai kuat tekan yang diperoleh masih termasuk kategori beton struktural mutu sedang menurut peraturan SNI 03-6468-2000. Nilai rata-rata kuat tekan beton pada umur 56 hari adalah $38.93 \mathrm{MPa}$ ( tanah diatomae 0\%); $33.31 \mathrm{MPa}$ (tanah diatomae 5\%); $29.56 \mathrm{MPa}$ (tanah diatomae 10\%); $26.65 \mathrm{MPa}$ (tanah diatomae 15\%). Nilai modulus elastisitas pada beton juga mengalami penurunan sebanding dengan penambahan kadar diatomae.
\end{abstract}

Kata kunci : Diatomae, Aditif, Kuat Tekan, Modulus Elastisitas.

\section{Pendahuluan}

Penggunaan bahan pozzolan dalam pembuatan beton sudah lama dan memiliki sejarah sukses, karena penggunaannya mendahului penemuan semen Portland setidaknya 20 abad yang lalu. Pozzolan didefinisikan sebagai bahan yang mampu bereaksi dengan kapur dengan adanya air pada suhu biasa untuk membentuk senyawa dengan sifat semen (cementitious compounds). Bahan pozzolan digunakan dalam industri semen saat ini meliputi produk alami seperti tuffs, abu keramik, batu apung, zeolit, diatomae, metakaolin, atau produk yang dihasilkan dari hasil pemanasan sebelum digunakan seperti fly ash, silica fume dan slag (Pimraksa \& Chindaprasirt, 2009).

Menurut Bastis (2004) keuntungan beton yang mengandung pozzolan adalah mempunyai permeabilitas rendah dan ketahanan tinggi dalam waktu lama terhadap serangan sulfat. Kelemahan pozzolan adalah dalam kadar yang banyak akan mengurangi kekuatan beton umur 28 hari dan membutuhkan waktu perawatan yang lama akibat reaksi pozzolanik yang lambat. 
Menurut Khan (1980) secara kimiawi, komposisi utama tanah diatomae berupa silika amorf yang kadarnya mencapai sekitar 55-70\%, tergantung lingkungan setempat. Kadar senyawa silika dalam tanah diatomae sangat bervariasi, demikian juga strukturnya. Hal ini sangat dipengaruhi oleh asalnya. Di samping itu tanah diatomae memiliki keunggulan berdaya serap tinggi, dapat diperbaharui, mudah diperoleh dengan harga yang tidak mahal dan bahan dasar yang merupakan sumber daya alam yang dapat dimanfaatkan untuk kesejahteraan masyarakat.

Penelitian ini menggunakan tanah diatomae sebagai aditif dengan memanfaatkan tanah diatomae yang belum dimanfaatkan secara optimal. Deposit tanah diatomae di Kabupaten Aceh Besar cukup tinggi dengan estimasi 40.353.700.00 ton (Dinas Pertambangan dan Energi Provinsi Aceh, 2012). Penggunaan tanah diatomae ini diharapkan dapat menghasilkan beton mutu normal dengan sifat dan karakteristik teknis yang mendekati mutu beton normal tanpa tambahan tanah diatomae.

\section{Tinjauan Kepustakaan}

Tanah diatomae dengan rumus kimia $\left(\mathrm{SiO}_{2} \mathrm{nH}_{2} \mathrm{O}\right)$ adalah batuan sedimen silika terutama yang terdiri dari sisa kerangka fosil tumbuhan air, ganggang yang bersel tunggal. Koloni diatomae akan berkembang baik apabila di tempat itu terdapat batuan piroklastik (mengandung banyak $\mathrm{SiO}_{2}$ ). Komposisi kimia diatomae terdiri dari $86 \%$ silika, 5\% natrium, 3\% magnesium dan $2 \%$ besi (Hidayati, 2007). Tanah diatomae dikenal dengan berbagai istilah seperti diatomit, kieselguhr, tripolit atau tepung fosil (Johnstone and Johnstone, 1961), atau tanah serap (Hoeve, 1984).

Berdasarkan American Society for Testing \& Materials (ASTM) jenis pozzolan berdasarkan asalnya dibagi menjadi dua kategori yaitu:

1. Natural (Pozzolan Alami) ASTM C 618 Class N Yang termasuk pozzolan alami seperti volcanic ash atau debu vulkanis, pumicite, tanah diatomae (diatomaceous earth), tufa (tuff), opaline shales dan opaline cherts

2. Processed (Manufactured) berdasarkan proses atau artifisial adalah

- Silica fume (ASTM C 1240)

- Fly Ash (ASTM C 215)

- $\quad$ Slag (ASTM C 989)

Tanah diatomae termasuk tipe SCM atau bahan tambahan pengganti sebagian semen alami berdasarkan ASTM C 618 Class N. Tanah diatomae memiliki sifat pozzolan yang mirip dengan bahan pozzolan lainnya seperti fly ash dan metakaolin (Sanchez de Rojas, 1999).

Penelitian yang dilakukan oleh Stamatakis, et al (2003) membandingkan bentuk tanah diatomae dari daerah yang berbeda, yaitu dari Hungaria dan Rumania. Diatomae dari Hungaria mengandung $\mathrm{SiO}_{2}$ lebih tinggi77,68\% yang disebabkan oleh Opal-A, sedangkan dari Rumania mengandung sekitar $75 \%$. Semakin tinggi kandungan RS dari diatomae maka semakin tinggi kekuatan beton. Indentifikasi Opal-A dapat dilihat pada Gambar 1. 

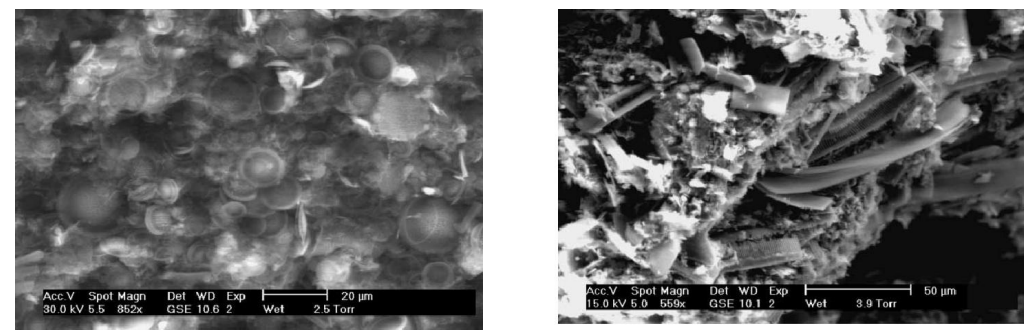

Gambar 1. Struktur (a) Tanah diatomae dari Hungaria berbentuk piring kecil;

(b) Tanah diatomae dari Rumania

Sumber : Stamatakis, et al (2003)

Kastis, et. al. (2006) melakukan penelitian dengan mengganti sebagian semen dengan diatomae $0 \%, 10 \%, 20 \%$ dan $35 \%$. Hasilnya menunjukkan bahwa campuran semen yang memiliki kandungan $10 \%$ diatomae, memiliki kekuatan tekan yang sama dan sesuai dengan semen Portland. Hasil penelitian Pimraksa dan Chindaprasirt (2009) menunjukkan bahwa tanah diatomae memiliki sifat pozzolan dan dapat digunakan untuk membuat batu bata ringan. Batu bata yang dibuat dengan diatomae dan $15 \%$ kapur serta $5 \%$ gypsum menunjukkan kekuatan yang cukup tinggi, yaitu $14,5 \mathrm{MPa}$ dan berat jenis yang rendah, yaitu $0,88 \mathrm{~g} / \mathrm{cm}^{3}$.

Secara umum bahan tambah yang digunakan beton dapat dibedakan menjadi dua yaitu bahan tambah yang bersifat kimiawi (chemical admixture) dan bahan tambah yang bersifat mineral (additive). Bahan tambahan kimiawi atau admixture adalah bahan-bahan yang ditambahkan kedalam campuran beton pada saat atau selama pencampuran itu berlangsung. Fungsi dari bahan tambahan ini adalah untuk memenuhi kecocokan beton untuk pekerjaan tertentu dalam hal mengubah sifat-sifat, menghemat biaya, waktu yang efisien dan lain-lain. Menurut ACI Committe 212.IR-81 (Revised 1986) yang selalu diperbaiki sejak 1944, 1954, 1963, 1971, jenis bahan tambahan untuk beton dikelompokan dalam lima kelompok yaitu: accelerating, air-entraining, water reducer, set-controling, finely devided mineral dan miscellaneous.

Bahan tambah mineral merupakan bahan tambah yang dimaksudkan untuk memperbaiki kinerja beton. Bahan tambah mineral ini cenderung bersifat penyemenan (cementitious). Beberapa bahan tambah mineral ini adalah pozzolan alami seperti abu vulkanik atau pumice, tanah diatomae, fly ash, slag, dan silica fume. Menurut SNI 2002 abu terbang atau bahan pozzolan lainnya yang digunakan sebagai bahan tambahan harus memenuhi "Spesifikasi untuk abu terbang dan pozzolan alami murni atau terkalsinasi untuk digunakan sebagai bahan tambahan mineral pada beton semen portland", (ASTM C 618).

Beberapa keuntungan penggunaan bahan tambah mineral ini antara lain (Cain, 1994: 500-508):

a. Memperbaiki kinerja workabilitas

b. Mengurangi panas hidrasi

c. Mengurangi biaya pekerjaan beton

d. Mempertinggi daya tahan terhadap serangan sulfat

Tinjauan Kuat Tekan Dan Modulus Elastisitas Beton Pada Campuran Diatomae Sebagai Aditif - Emi Maulani 
e. Mempertinggi daya tahan terhadap serangan reaksi alkali-silika

f. Mempertinggi usia beton

g. Mempertinggi kekuatan tekan beton

h. Mempertinggi keawetan beton

i. Mengurangi penyusutan

$\mathrm{j}$. Mengurangi porositas dan daya serap air dalam beton.

John (2003) menegaskan bahwa beton ramah lingkungan pada era modern ini dapat dicapai dengan campuran beton yang mengkombinasikan beberapa kualitas agregat disertai bahan tambah. Salah satu upaya mencapai beton ramah lingkungan adalah mengupayakan pengurangan pemakaian semen dengan memakai pozzolan, memproduksi semen campuran (blended cement), mengaplikasikan jenis-jenis agregat alternatif, serta mengimplementasikan material daur ulang sebagai bahan campuran beton.

Dalam SK SNI M-14-1989-E dijelaskan pengertian kuat tekan beton yakni besarnya beban per satuan luas yang menyebabkan benda uji beton hancur bila dibebani gaya tekan tertentu, yang dihasilkan oleh mesin tekan. Selanjutnya Mulyono (2006) mengemukakan bahwa kuat tekan beton mengidentifikasikan mutu sebuah struktur di mana semakin tinggi tingkat kekuatan struktur yang dikehendaki, maka semakin tinggi pula mutu beton yang dihasilkan.

Salah satu masalah yang sangat berpengaruh pada kuat tekan beton adalah adanya porositas. Semakin besar porositasnya maka kuat tekannya semakin kecil, sebaliknya semakin kecil porositas kuat tekannya semakin besar. Besar dan kecilnya porositas dipengaruhi oleh besar dan kecilnya FAS yang digunakan. Semakin besar nilai FAS porositas semakin besar, sebaliknya semakin kecil FAS porositas semakin kecil.

Menurut Wang dan Salmon (1990) kuat tekan yang terjadi dapat dihitung dengan Persamaan 1.

$$
f^{\prime} c=\frac{P_{M a x}}{A}
$$

Dimana :

$f_{c}^{\prime} \quad=$ Tegangan beton yang timbul $(\mathrm{MPa}) ;$

$P_{\mathrm{Max}} \quad=$ besar beban maksimum yang bekerja $(\mathrm{N})$;

$A \quad=$ luas tampang benda uji $\left(\mathrm{mm}^{2}\right)$.

Regangan beton dapat dihitung dengan Persamaan 2.

$$
\varepsilon=\frac{\Delta l}{l}
$$

Dimana :

$\varepsilon=$ Regangan beton;

$\Delta l=$ Perpendekan benda uji $(\mathrm{cm})$;

$l=$ panjang benda uji sebelum pembebanan $(\mathrm{cm})$. 
Menurut Wang dan Salmon (1990), modulus elastisitas $(E)$ dihitung pada saat tegangan mencapai $25 \%$ sampai $50 \%$ dari kuat tekan $\left(f^{\prime}{ }_{c}\right)$ beton. Modulus elastisitas beton adalah perbandingan antara besarnya kuat tekan rata-rata $\left(0,375 f^{\prime} c\right)$ dengan regangan $(\varepsilon)$ pada $0,375 f^{\prime}$, , sehingga modulus elastisitas dapat dihitung dengan Rumus 3.

$$
E=\frac{0,375 f^{\prime} c}{\mathcal{E}_{\left(0,375 f^{\prime} c\right)}}
$$

Dimana :

$$
\begin{array}{ll}
E & =\text { Modulus elastisitas beton }\left(\mathrm{kg} / \mathrm{cm}^{2}\right) ; \\
\mathcal{E}_{\left(0,375 f^{\prime} c\right)} & =\text { regangan beton pada saat } 0,375 f^{\prime}{ }_{c} ;
\end{array}
$$

\section{Metode Penelitian}

Pada penelitian ini direncanakan campuran beton dengan faktor air semen (FAS) 0.30. Untuk masing-masing campuran, tanah diatomae yang ditambahkan dalam adukan mortar beton dengan persentase $0 \%, 5 \%, 10 \%$, dan $15 \%$.

Tanah diatomae yang dipakai mempunyai spesific gravity sebesar 1.5 dan komposisi kimia sebagai berikut: $62,28 \% \mathrm{SiO}_{2}, \mathrm{CaO} 8,28 \%, \mathrm{Fe}_{2} \mathrm{O}_{3} 1,79 \%$ dan $\mathrm{Al}_{2} \mathrm{O}_{3}$ 9,52\%.

Sebagai agregat digunakan pasir halus, pasir kasar dan kerikil yang berasal dari Sungai Krueng Aceh dan mempunyai sifat fisis seperti pada Tabel 1.

Tabel 1. Sifat fisis agregat

\begin{tabular}{|l|c|c|c|c|}
\hline \multirow{2}{*}{ Agregat } & \multirow{2}{*}{ Berat Volume } & \multicolumn{2}{|c|}{ Specific Gravity } & \multirow{2}{*}{\begin{tabular}{c} 
Fineness \\
\cline { 3 - 4 }
\end{tabular}} \\
\cline { 3 - 4 } & & OD & SSD & Modulus \\
\hline Pasir halus & 1,62 & 2,57 & 2,63 & 2,31 \\
\hline Pasir kasar & 1,79 & 2,57 & 2,64 & 4,65 \\
\hline Kerikil & 1,82 & 2,77 & 2,81 & 6,68 \\
\hline
\end{tabular}

Sebagai semen digunakan semen Portland produksi Semen Andalas. Air untuk pencampuran beton yang digunakan adalah air dari PDAM Tirta Daroy.

Benda uji yang digunakan adalah silinder berdiameter $100 \mathrm{~mm}$ dan tinggi $200 \mathrm{~mm}$. Pengujian tekan dilakukan pada saat benda uji berumur 7 hari, 28 hari dan 56 hari. Jumlah benda uji untuk masing-masing persentase adalah sebanyak 3 buah benda uji. Rencana campuran beton untuk $1 \mathrm{~m} 3$ volume beton diperlihatkan pada Tabel 2. 
Tabel 2. Rencana campuran beton (Mix Design)

\begin{tabular}{|c|c|c|c|c|c|c|c|}
\hline \multirow{2}{*}{ FAS } & \multirow{2}{*}{$\begin{array}{c}\text { Persentase } \\
\text { Diatomae }\end{array}$} & Air & Semen & Kerikil & $\begin{array}{c}\text { Pasir } \\
\text { Kasar }\end{array}$ & $\begin{array}{c}\text { Pasir } \\
\text { halus }\end{array}$ & $\begin{array}{c}\text { Tanah } \\
\text { diatomae }\end{array}$ \\
\cline { 3 - 8 } & $0 \%$ & 192.62 & 642.05 & 927.77 & 231.94 & 386.57 & 0 \\
\cline { 2 - 8 } & $5 \%$ & 192.62 & 642.05 & 927.77 & 231.94 & 367.24 & 19.33 \\
\cline { 2 - 8 } & $10 \%$ & 192.62 & 642.05 & 927.77 & 231.94 & 347.92 & 38.657 \\
\cline { 2 - 8 } & $15 \%$ & 192.62 & 642.05 & 927.77 & 231.94 & 328.58 & 57.98 \\
\hline
\end{tabular}

\section{Hasil dan Pembahasan}

4.1 Hasil

Kuat Tekan Beton, besarnya kuat tekan beton rata-rata dapat dilihat pada Tabel 3 berikut

Tabel 3 Kuat tekan beton rata-rata dengan diatomae sebagai aditif

\begin{tabular}{|c|c|c|c|c|c|}
\hline \multirow{2}{*}{ FAS } & $\begin{array}{c}\text { Variasi } \\
\text { Persen } \\
\text { Diatomae }\end{array}$ & \multicolumn{2}{|c|}{ Kuat Tekan Rata-rata (MPa) } & \multirow{2}{*}{ Mutu Beton } \\
\cline { 2 - 5 } & $\mathbf{7}$ Hari & $\mathbf{2 8 ~ H a r i}$ & $\mathbf{5 6}$ Hari & \\
\hline \multirow{3}{*}{$\mathbf{0 . 3}$} & $0 \%$ & 31.23 & 33.10 & 38.93 & Structural Concrete \\
\cline { 2 - 6 } & $5 \%$ & 28.52 & 30.18 & 33.31 & Structural Concrete \\
\cline { 2 - 5 } & $10 \%$ & 23.73 & 26.85 & 29.56 & Structural Concrete \\
\cline { 2 - 5 } & $15 \%$ & 22.90 & 23.73 & 26.65 & Structural Concrete \\
\hline
\end{tabular}

Hubungan kuat tekan beton dan persentase aditif tanah diatomae diperlihatkan pada Gambar 2.

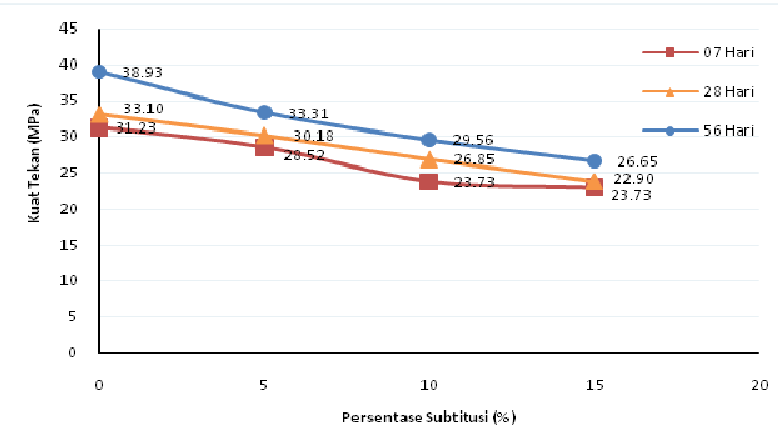

Gambar 2 Grafik hubungan kuat tekan beton dengan persentase tanah diatomae sebagai aditif dengan FAS 0.30

Dari Gambar 2 terlihat bahwa kuat tekan beton menurun sebanding dengan meningkatnya persentase tanah diatomae. Namun demikian, sampai persentase sebanyak $15 \%$ beton yang dihasilkan masih termasuk kategori beton struktural 
mutu sedang, karena kuat tekan yang dihasilkan berada pada selang 21-40 MPa (SNI 03-6468-2000).

Pertumbuhan kuat tekan beton dengan diatomae sebagai bahan tambah diperlihatkan pada Gambar 3.

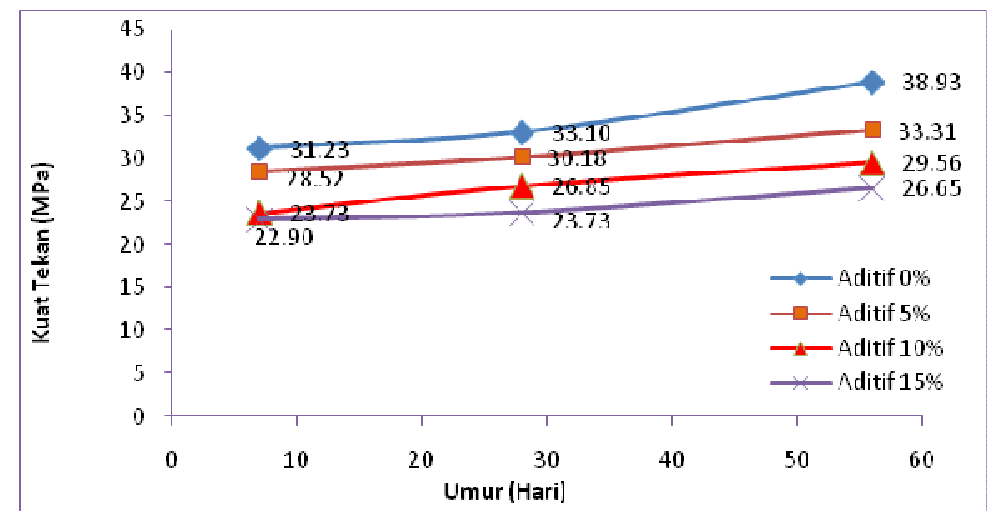

Gambar 3 Grafik perkembangan kuat tekan beton dengan variasi persentase aditif tanah diatomae FAS 0.30

Dari gambar 3 dapat diketahui bahwa campuran beton untuk diatomae yang digunakan sebagai bahan tambah kuat tekan beton juga meningkat seiring dengan meningkatnya umur pengujian dari umur 7 hari sampai dengan umur beton 56 hari.

Hubungan kuat tekan dan berat volume beton dengan diatomae bahan tambah diperlihatkan pada Gambar 4.

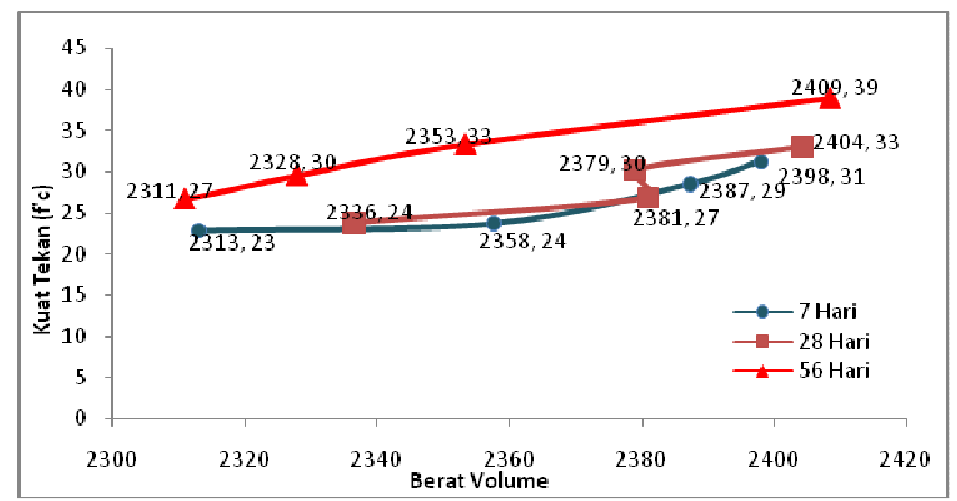

Gambar 4 : Grafik hubungan kuat tekan dan berat volume beton dengan diatomae sebagai bahan tambah

Dari gambar 4 terlihat kecenderungan bahwa semakin meningkatnya berat volume beton kuat tekannya juga semakin meningkat. Dan sebaliknya semakin menurunnya kuat tekan beton dengan meningkatnya penambahan persentase tanah diatomae maka semakin menurun pula berat volume beton. 
Hubungan modulus elastisitas dan kuat tekan beton dengan diatomae sebagai bahan tambah diperlihatkan pada Gambar 5.

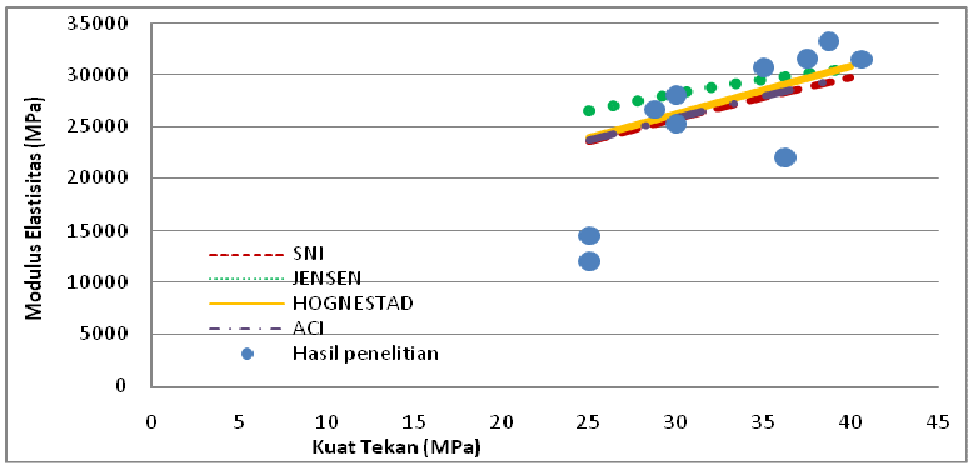

Gambar 5 : Grafik hubungan kuat tekan beton dan modulus elastisitas dengan diatomae sebagai aditif

Dari Gambar 5 terlihat bahwa modulus elastisitas meningkat seiring dengan meningkat kuat tekan beton. Pada gambar tersebut juga di plot hubungan modulus elastisitas dan kuat tekan beton berdasarkan rumus empiris yang diusulkan Hognestad, Jensen, ACI.

Modulus elastisitas yang diperoleh berada pada garis persamaan, kecuali dua data dengan kuat tekan sebesar $24 \mathrm{MPa}$ dimana modulus elastisitas yang diperoleh lebih rendah dari yang dihitung dengan persamaan. Data tersebut adalah data beton dengan tambahan tanah diatomae sebesar $15 \%$.

Untuk memprediksi kuat tekan beton dengan diatomae maka diusulkan persamaan untuk menghitung kuat tekan beton tersebut. Data semua kuat tekan pada berbagai persentase diatomae yang digunakan dinormalisasi dengan kuat tekan beton tanpa penggunaan diatomae (diatomae $=0 \%)$.

Data hasil pengujian di laboratorium bersama dengan persamaan yang diusulkan di atas di plot pada Gambar 6.

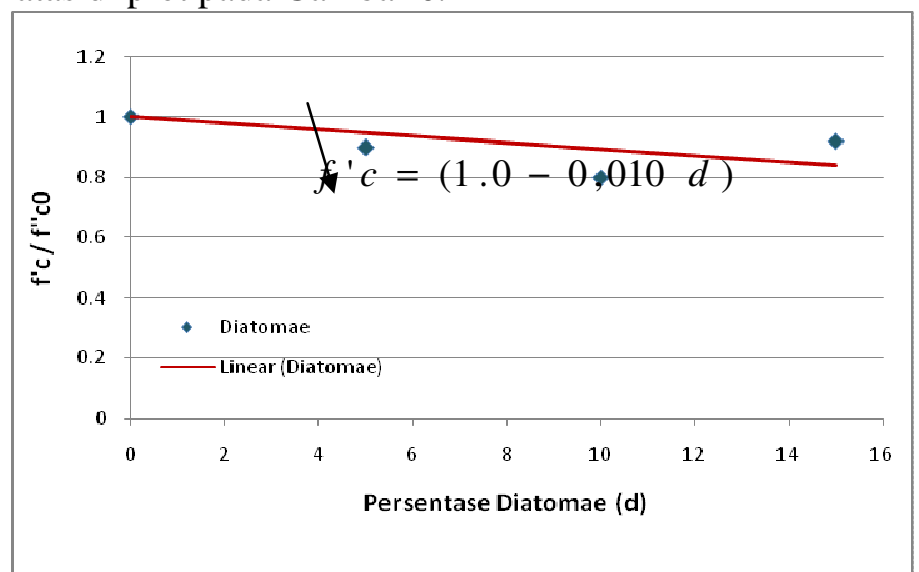

Gambar 5. Persamaan untuk memprediksi kuat tekan beton dengan diatomae sebagai aditif beserta data hasil pengujian. 


\section{Kesimpulan dan Saran}

\subsection{Kesimpulan} berikut :

Berdasarkan hasil penelitian ini diperoleh beberapa kesimpulan sebagai

1. Tanah diatomae dari Desa Lampanah bisa digunakan sebagai salah satu material aditif mineral.

2. Beton struktural dapat dihasilkan sampai persentase diatomae sebanyak $15 \%$.

3. Modulus elastisitas meningkat seiring dengan meningkat kuat tekan beton. Modulus elastisitas yang diperoleh berada pada garis persamaan yang diajukan oleh Hognestad, Jensen, ACI dan SNI.

\subsection{Saran}

Penelitian ini diharapkan dapat dilanjutkan oleh para peneliti lainnya, terutama terhadap beberapa permasalahan berikut :

1. Penelitian lanjutan terhadap tanah diatomae dapat dilakukan dengan perhitungan mix design berdasarkan perbandingan volume karena berat jenis tanah diatomae sangat rendah.

2. Untuk pengujian umur beton perlu dilakukan penelitian lebih lanjut terhadap sifat mekanis beton untuk umur 90 hari.

\section{Daftar Kepustakaan}

ASTM., 1995. Concrete and Agregat, Philadelphia: Annual Book of ASTM Standard Vo.04.02.1995.

Dipohusodo, I., 1999. Struktur Beton Bertulang Berdasarkan SK SNI T-151991-03 Departemen Pekerjaan Umum RI. Jakarta, Gramedia Pustaka Utama.

European Committee for Standardisation., 2000. Cement-Part 1: Composition, specifications and conformity criteria for common cements. European Standard EN 197-1, Brussels, 2000. 28 pp.

Fragoulis, D, Stamatakis, M. G, Papageorgio, dan Chaniotakis, E., 2005. The physical and mechanical properties of composite cements manufactured with calcareous and clayey Greek diatomite mixtures. Journal Cement \& Concrete Composites 27 (2005) 205-209.

Humphreys, K., dan Mahasenan, M., 2002. "Climate Change", Towards a Sustainable Cement Industry, Battelle-World Council for Sustainable Development.

Kastis, D, Kakali, G, Tsivilis, S, dan Stamatakis, M. G., 2006. Properties and hydration of blended cements with calcareous diatomite. Cement and Concrete Research 36 (2006) 1821-1826

Kurtis, K., 2002. Supplementary Cementing Materials. Georgia Tech, PCA CD038, School of Civil and Environmental Engineering Georgia Institute of Technology Atlanta, Georgia.

Tinjauan Kuat Tekan Dan Modulus Elastisitas Beton Pada Campuran Diatomae 
Meyer, C. 2002, Concrete and Sustainable Development, Special Publication ACI 206, Concrete Materials to Application - A Tribute to Surendra P. Shah, American Concrete Institute, Farmington Hills, MI

NRMCA., 2000, Concrete in Practise: what, Why, and How, CIP30Supplementary Cementitious Materials, Silver Spring, MD.

Naik, TR. 2005. Sustainability of Concrete and Cement Industries, CBU-200415;REP-562, January, Center for By-Products Utilizatons, Department of Civil Engineering and Mechanics, College of Engineering and Applied Science, The University of Wisconsin, Milwaukee, USA.

Pimraksa, K, dan Chindaprasirt, P., 2009. Lightweight bricks made of diatomaceous earth, lime and gypsum. Ceramic International Res (2009) 471-478

RockTron., 2007.“A Brief History of Pozzolans, PFA, and Cement”, www.rocktronplc.com/PDFs/A\%20Brief\%20History\%20of\%20Pozzolans, \%20PFA \%20\&\%20Cement.pdf.

Sanchez de Rojas, M. I, J. Rivera, dan M. Frias., 1999. Influence of the microsilica state on pozzolanic reaction rate. Cem. Concr. Res. 29 (1999) 945-949.

SNI 03-2847-2002, Tata cara perhitungan struktur beton untuk bangunan gedung. Bandung, Desember 2002.

T.Y. Lin, 1996. Desain struktur beton prategang I. Penerbit Erlangga, Jakarta. 